\title{
Surgical Resection of Odontogenic Inflammatory Maxillary Cyst: Case Report and Review of Literature
}

\author{
\begin{tabular}{|l|}
\hline \multicolumn{1}{|c|}{ Sorina Cosma ${ }^{1^{*}}$, Sorin Cimpean ${ }^{2}$} \\
${ }^{1}$ ENT department and maxillofacial surgery, $\mathrm{CH}$ Manchester Charleville-Mezieres, France \\
${ }^{2}$ General Surgery, CHU Saint Pieter, Brussels
\end{tabular}
}

*Corresponding Author: Sorina Cosma, ENT department and maxillofacial surgery, CH Manchester Charleville-Mezieres, France, E-mail: sorinacampean@yahoo.com

Received Date: May 30, 2018 Accepted Date: June 15, 2018 Published Date: June 22, 2018

Citation: Sorina Cosma, Sorin Cimpean (2018). Surgical Resection of Odontogenic Inflammatory Maxillary Cyst: Case Report and Review of Literature. POJ Dent Oral Care. 2(1):1-5.

\begin{abstract}
Background

Odontogenic inflammatory maxillary cysts constitute pathology for which clinical, radiological and evolutionary aspects are considerably polymorphic. For small cystic lesions non-surgical endodontic treatment is used. Larger lesions, however, have a natural tendency to grow and weaken the bone (as well as an inflammatory risk) may be treated by surgery.
\end{abstract}

\section{Case presentation}

We present a case report of surgical resection of a large maxillary cyst on a patient who previously had multiple dental extractions until complete edentation.

\section{Conclusion}

Great cystic maxillary lesions are relatively rare. A definitive diagnosis cannot be determined based on the history, clinical and radiographic evaluation. A correct pre-operative diagnosis is very difficult and can only be possible after histological examination.

Keywords: Dental-radicular cyst, Radiolucency, Maxilla, Enucleation

\section{Background}

Cystic lesions of the maxilla could be unilocular or multilocular, usually with well-defined sclerotic borders and can be cysts and tumors. According to the World Health Organization's 1992 classification, the odontogenic cysts associated with inflammation are: the apical cyst, radicular cyst, residual cyst and paradental cyst $[1,2,3]$.

On the etiopathogenic level, the radicular cysts are clinical entities belonging to the chronic line of periodontitis apical which derived from epithelium associated with the development of the dental apparatus [4].

The apical cyst is the most common cystic lesions of the maxillary and is more common after the first decade with a peak in the $3 \mathrm{rd}$ and 5 th decades and a predilection in men. It is localized preferentially at the sector level of the maxillary anterior and at the level of molars $[5,6,7]$. The radicular cysts develop slowly and the patients do not experience pain unless acute inflammatory exacerbation is present. The growth rate has been estimated at about $5 \mathrm{~mm}$ per year [8]. The lesions are often detected only during routine radiographic examination. If the cyst does become large, symptoms such as swelling, mild sensitivity, tooth mobility and displacement may be observed. The affected tooth is non-responsive to thermal and electrical pulp tests [9].

The differential diagnosis should be made with all bone lesions with radiolucency.

Management of the odontogenic cyst is extraction of the impacted tooth and enucleation of cyst. In large cysts, first apply marsupialization to reduce size of the cyst. When cyst becomes of sufficiently small size, operation enucleation and tooth extraction could be considerated $[10,11]$.

Copyright: ${ }^{\circledR} 2018$ Sorina Cosma, et al. This is an open-access article distributed under the terms of the Creative Commons Attribution License, which permits unrestricted use, distribution, and reproduction in any medium, provided the original author and source are credited. 


\section{Case presentation}

34 years-old male came to the Dental Service of our Hospital for dental care. The patient complains of a flow in the mouth and a painful swelling in the upper right gum.

The patient does not have a particular medical history.

The extra-oral examination has not shown a swelling or facial asymmetry and the intra-oral examination revealed a complete edentation following multiple dental removals. We found on palpation at the level of the upper right vestibule a depressible swelling, not very sensitive, with approximately $2 \mathrm{~cm}$. The overlying mucosa was intact, normal in colour. The examination of the right nasal cavity does not find any lesions or swelling at the floor.

The laboratory exams didn't find any deviation from normal ranges.

A panoramic radiography shows an ovoid well defined with osteosclerotic border radiolucent lesion on the right maxilla extending from 21 up to 22 and measuring approximately $2 \mathrm{~cm}$ in diameter (Figure 1). The cystic lesion does not cross the floor of the nasal cavity and we see also the teeth in bad health with granulomas and root level infection. The CT scan reveals a cyst that measures $20 \times 18 \mathrm{~mm}$, with a regular contour and liquid content, located at the level of the alveolus maxilla teeth 21 and 22 (Figure 2).

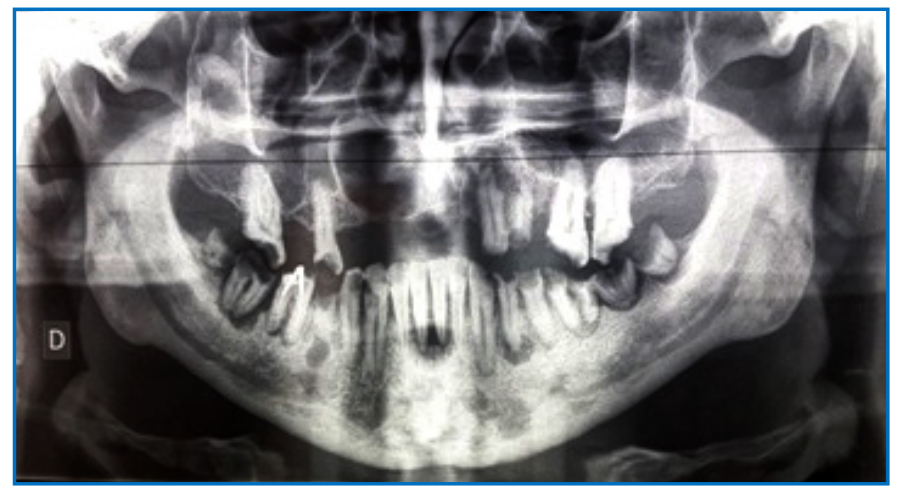

Figure 1: The radiographic image of the right maxillary cyst

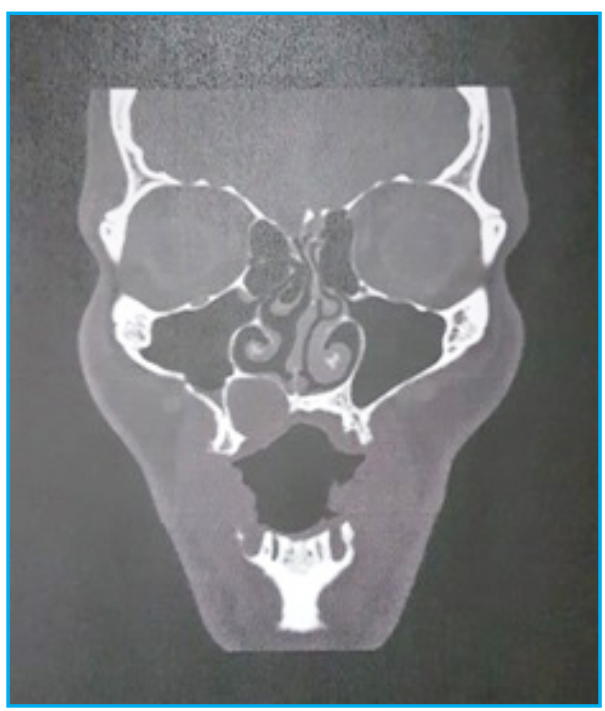

Figure 2: The CT image of the cyst in coronal section

\section{Surgical treatment}

The patient underwent a surgical treatment. The intervention was done under general anesthesia. Xylocaine 1\% adrenaline is infiltrated at the level of the upper right gum. We practiced Newman's trapezoid flap in the gingival mucosa (Figure 3). We roughen the mucosa and we came across a whitish flow. A sample for bacteriological exam was taken. We removed all the mucosa that caps the cystic cavity. Bone continuity exists neither with the nasal cavities nor with the palate (Figure 4). We place the hemostatic dressing in the cavity. The gingival mucosa was closed with resorbable stitches. The hemostasis was satisfactory (Figure 5).

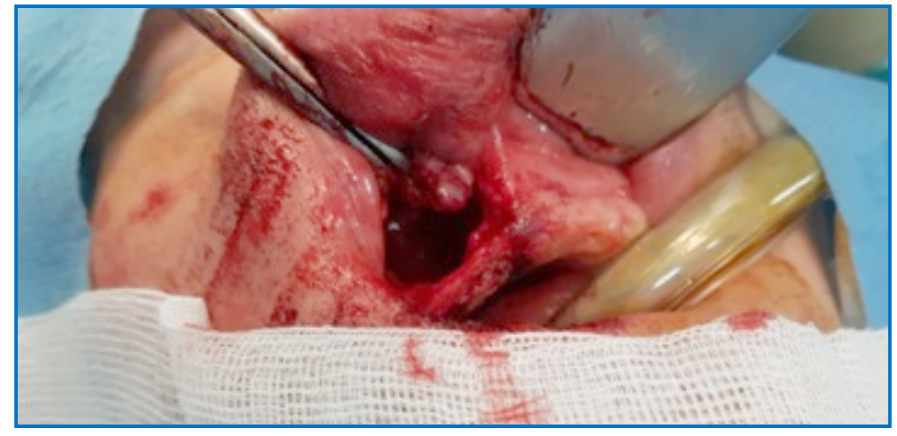

Figure 3: Intraoperative image with open cystic cavity.

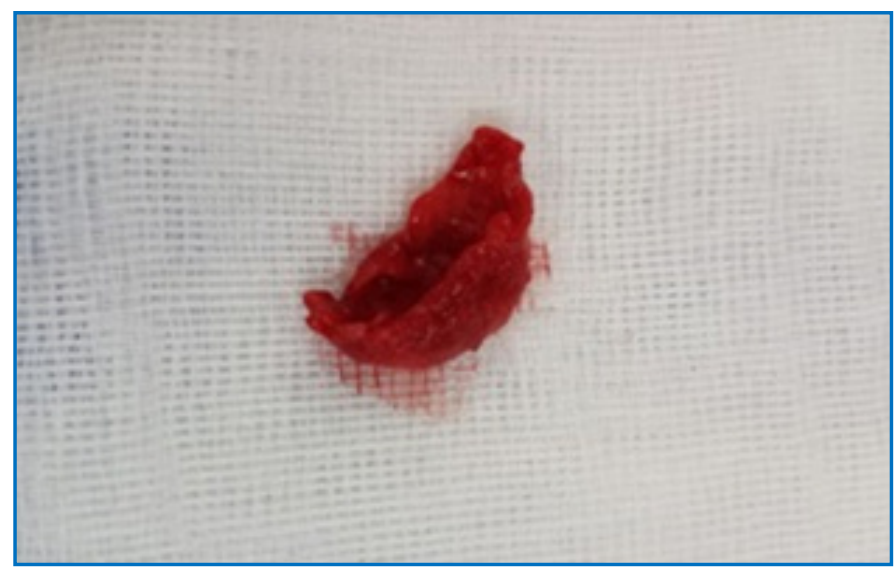

Figure 4: All the cystic mucosa was removed.

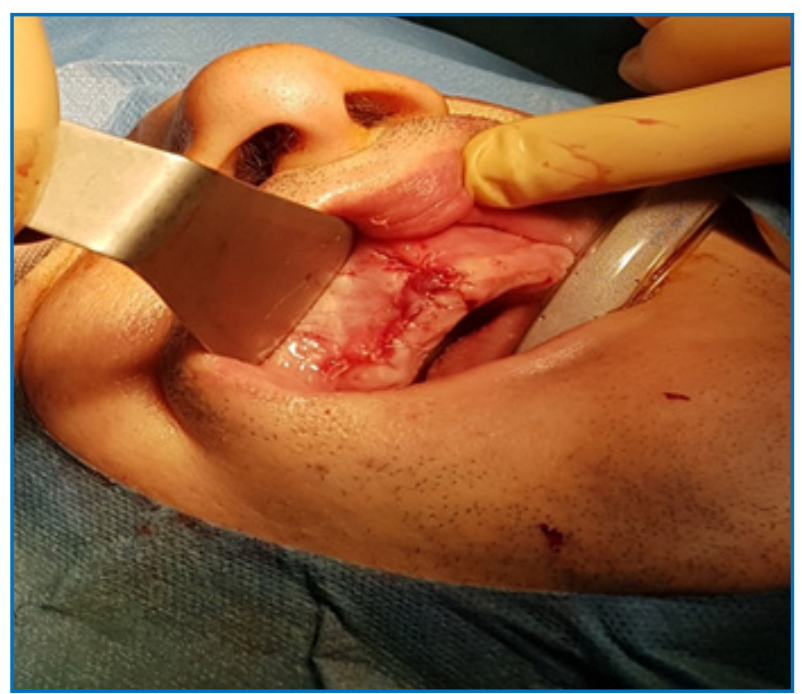

Figure 5: Closing the mucosal flap

Citation: Sorina Cosma, Sorin Cimpean (2018). Surgical Resection of Odontogenic Inflammatory Maxillary Cyst: Case Report and Review of Literature. POJ Dent Oral Care. 2(1):1-5. 


\section{Postoperative course}

The post-operative course was marked by a swelling of the right hemi-face which disappeared in a few days after the application of cold compresses. The medical treatment consisted in mouthwash, analgesic and general spectrum antibiotic like beta-lactam class. The culture of the liquid in the cyst found Streptoccocus constellatus sensitive to the antibiotic already administered.

The patient was discharged from the hospital on the 1st postoperative day. Three months later the clinical control found a good healing gum and the control radiography found the cystic cavity beginning to fill with bone (Figure 6).

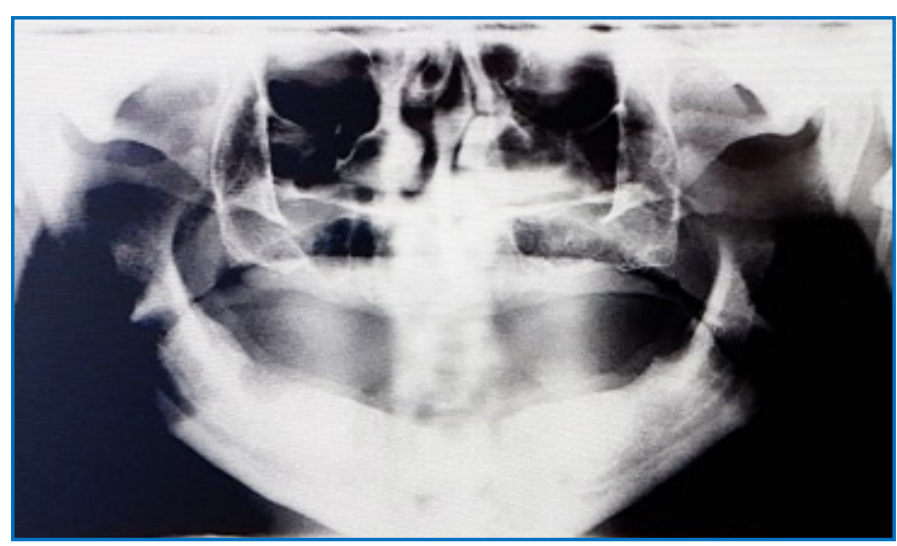

Figure 6: Radiographic appearance at 3 months postoperative

\section{Anatomo-pathological results}

The histopathologic exam shows appearance consistent with an apico-dental cyst and the absence of any atypical character.

\section{Discussion}

A wide variety of cysts and neoplasms may occur in the maxillofacial region. The most important of these are maxillary cysts [12]. Growth of a cyst is typically slow, centrifugal and infiltrative [13]. Radicular cysts are thought to arise from epithelial cell rests of Malassez in the periodontal ligament, and they are believed to proliferate as a result of periapical inflammation caused by infection of the root canal system. They are particularly frequent in the maxillary anterior region, presumably as a result of trauma [14].

The impossibility of distinguishing a cyst from a granuloma led the researchers to perform statistics from postoperative pathological examinations. The results showed that the percentage of cyst ranged from 6 to 55\% [15].

The cyst may displace adjacent teeth or cause mild root resorption. Radicular cysts and periapical granulomas have a similar radiographic appearance [16]. The radiological assessment must assess the relationship of the cyst with the causal tooth(s), but also with the neighboring teeth, the possible rhizalyses and the relations with the neighboring organs: nasal fossae, maxillary sinus, pterygomaxillary fossa [17].

\section{Clinical findings}

The odontogenic inflammatory cysts may be asymptomatic, the discovery is fortuitous on the occasion of a routine radiographic examination, or the clinical signs related to the expansion of the cyst and the dental displacements it causes are confused with the others odontogenic tumors [18]. If the cyst does become large, symptoms such as swelling, mild sensitivity, tooth mobility and displacement may be observed [19]. During their evolution, the radiculodental cysts, go through 4 stages: latency phase, deformation phase, externalization phase, fistulization phase $[20,21]$.

\section{Differential diagnosis}

The differential diagnosis of the radicular cysts should include dentigerous cyst [DC], pindborg tumor, periapical cementoma, traumatic bone cyst, ameloblastoma, odontogenic keratocyst and odontogenic fibroma [22]. Occasionally mucoepidermoid carcinoma arising from mucous cells within the cyst walls and squamous cell carcinoma [23]. In addition to the histopathologic differences between the feature of the epithelium of OIC and DC, the differential diagnosis can also include the development and the recurrence tendency of these cysts. Recently, researches showed mutation of PTCH gene and over activation of Shh signaling may be associated with the clinic pathological expression of OKC [24].

\section{Diagnosis}

The odontogenic tumor pathology of the facial mass is dominated by maxillary cysts mild [25]. According to the World Health Organization's 1992 classification, odontogenic cysts include the apical cyst, lateroradicular cyst, residual cyst, and paradental cyst.

Sometimes an orientation of diagnostic depending on: the appearance of the lesion [lytic, condensing, with bone formation, etc.], its limited character or not, the presence or absence of calcification, the seat [maxillary, mandibular, angle, toothed portion, condyle, etc.], relationships with adjacent dental apices [displacement, lysis, etc.], the possible presence of included teeth and previous traumas [26].

On the radiological level, the radiculodental cyst is presented by a unilocular radiolucent image at the apex of a mortified tooth $[27,28]$. The scanner allows the study of maxillary cysts by appreciating their volume and the anatomical surrounding zones [29]. According to Hisatomi et al, MRI is the only examination that can differentiate a non-cystic tumor (polymorphous adenoma, fibroids, granuloma) of a cystic tumor [30]. Histologically, a dental radicular cyst is defined by different components [31,32].

\section{Treatment options}

The major maxillary cysts, have one thing in common: surgical treatment [33]. The best therapeutic action is the enucleation of the lesion with anatomopathological examination of the entire excision piece. Surgery under general anesthesia is first-line in the treatment of large maxillary cysts.

Marsupialization is a surgical technique that can serve as a preamble to the excision of some cysts with fluid content. Suzuki treated 97 cases of various maxillary cysts by the irrigation

Citation: Sorina Cosma, Sorin Cimpean (2018). Surgical Resection of Odontogenic Inflammatory Maxillary Cyst: Case Report and Review of Literature. POJ Dent Oral Care. 2(1):1-5. 
method [34]. Cryotherapy is used in addition to surgery after enucleation of the cyst [35].

The recommended treatment option available for radicular cyst is the conventional endodontic approach combined with decompression or surgical enucleation of a cyst with extraction of the offending tooth [36,37]. In large lesions the endodontic treatment alone is not efficient and it should be associated with a decompression or a marsupialisation or even with enucleation $[38,39]$. When the lesion is small with approximately $1 \mathrm{~cm}$ in diameter, most clinicians opt for conventional endodontic treatment [40]. Few studies are of the opinion that regenerative techniques are not superior, either with regard to the speed or quality of healing $[41,42]$.

\section{Post-operative complications}

Like any surgery, bleeding and infection are possible. There is specific complication too. The fracture of the mandibular angle is usually due to the presence of a bulky cyst weakening this angle. The nerve injuries mainly concern the V3, lingual and mental nerves. The communication between the mouth and the sinus is due to a rupture of the sinus membrane. The way to go is to set up hemostatic compressions with waterproof closure by pedicle flap displaced coronal possibly with the use of the adipose mass of the face for syssarcoplasty $[43,44]$.

\section{Our course of action}

The therapeutic decision was to perform the enucleation of the cyst under general anesthesia. Because the patient presented complete edentation he didn't need an apical treatment, which left us to perform the enucleation of the cyst. The enucleation was chosen as a surgical technique because of the size of the cyst. The patient, being young and with dental problems for a long time, needed a radical treatment and benefited from explanations about the time to heal the remaining cavity in the bone. He needed a denture pretty soon, not only for aesthetic reasons but especially to be able to feed himself.

\section{Conclusion}

The great cystic maxillary lesions are relatively rare. A definitive diagnosis cannot be determined based on the history, clinical and radiographic evaluation. The correct diagnose can be possible only after histological examination. In the case reported here a decrease in the radiolucent area was already observed at 3 months after the surgery.

\section{References}

1. Sauveur G, Ferkdadji L, Gilbert E, Mesbah M. Kystes des maxillaires. Encycl Méd Chir (Elsevier SAS, Paris), Stomatologie, 2006;22-062-G-10, Médecine buccale, 2008;28-550-G-10.

2. Shen J, Fan M, Chen X, Wang S, Wang L, Li Y. Glandular odontogenic cyst in China: report of 12 cases and immunohistochemical study. J Oral Pathol Med. 2006;35(3):175-182.

3. Neville B, Damm D, Allen C, Bouquot J. Cistos e Tumores odontogênicos. In: Neville B, Damm D, Allen C, Bouquot J. Patologia Oral Maxilofacial. 3rd ed. Rio de Janeiro: Elsevier; 2009. p. 565-84.
4. Sasmita IS, Lusi Epsilawati, Pramanik F. Prevalence of the Dentigerous Cyst in Indonesian people using Panoramic Radiograph. J Int Dent Med Res. 2017;10(1):108-110.

5. Kamil Serkan Agacayak, Ibrahim Kose, Nedim Gunes, Emrullah Bahsi, Ferhan Yaman, Serhat Atilgan. Dentigerous Cyst with an Impacted Canine: Case Report. J Int Dent Med Res. 2011;4(1):21-24.

6. Vikalp Rastogi, Prashant K. Pandilwar. Calcifying epithelial odontogenic cyst associated with complex odontome of maxilla. J Maxillofac Oral Surg. 2013;12(1):85-89.

7. Ofer Mardinger, Yonatan Ben Zvi, Gavriel Chaushu, Josep Nissan, Yifat Manor. A retrospective analysis of replacing dental implants in previously failed sites. Oral Surg Oral Med Oral Pathol Oral Biol. 2012;114(3):290-293.

8. Marjorie Kerry Herd, Robert JR Smith, Peter A Brennan. Long buccal nerve block: a previously unreported complication. Oral Surg Oral Med Oral Pathol Oral Radiol Endod. 2011;112(2):1-3.

9. Lin LM, Ricucci D, Lin J, Rosenberg PA. Nonsurgical root canal therapy of large cyst-like inflammatory periapical lesions and inflammatory apical cysts. J Endod. 2009;35(5):607615.

10. Girish G, Mahesh Kumar R, Umashankar DN, Rashi Sharma, Veeresh $\mathrm{M}$, Ambika Bhandari. Dentigerous cyst in maxillary sinus: a rare occurrence. Int J Oral Maxillofac Pathol. 2011;2(2):20-23.

11. Buyukkurt MC, Omezli MM, Miloglu O. Dentigerous cyst associated with an ectopic toothin the maxillary sinus: a report of 3 cases and review of the literature. Oral Surg Oral Med Oral Pathol Oral Radiol Endod. 2010;109(1):6771.

12. Nair PN, Sundqvist G, Sjögren U. Experimental evidence supports the abscess theory of development of radicular cysts. Oral Surg Oral Med Oral Pathol Oral Radiol Endod. 2008;106(2):294-303.

13. Ximena Zornosa, Susan Müller. Calcifying Cystic Odontogenic Tumor. Head Neck Pathol. 2010;4(4):292-294.

14. Lin LM, Huang GT, Rosenberg PA. Proliferation of epithelial cell rests, formation of apical cysts, and regression of apical cysts after periapical wound healing. J Endod. 2007;33(8):908-916.

15. Gulten UNLU, Serkan AGACAYAK, Vedat TARI, Hilal ALAN. Odontogenic Abscess: A Retrospective Study (549 Case Between 1998-2008). J Int Dent Med Res. 2009;2(3):77-80.

16. Kaplan I, Anavi Y, Hirshberg A. Glandular odontogenic cyst: A challenge in diagnosis and treatment. Oral Dis. 2008;14(7):575-581.

17. Fouzia Hakkou, Saliha Chbicheb, Imane Achour, Wafae El Wady. Kystes inflammatoires des maxillaires: mise au point. Actual. Odonto-Stomatol. 2012;260:301-311.

18. George R, Donald PM, Sabarinath B. Calcifying cystic

Citation: Sorina Cosma, Sorin Cimpean (2018). Surgical Resection of Odontogenic Inflammatory Maxillary Cyst: Case Report and Review of Literature. POJ Dent Oral Care. 2(1):1-5. 
odontogenic tumor: A case report and review. IJSS Case Reports \& Reviews. 2015;1(8):28-31.

19. Sumer AP, Celenk P, Sumer M, Telcioglu NT, Gunhan O. Nasolabial cyst: case report with $\mathrm{CT}$ and MRI findings. Oral Surg Oral Med Oral Pathol Oral Radiol Endod. 2010;109(2):92-104.

20. Sudeendra Prabhu, K Rekha, GS Kumar. Glandular odontogenic cyst mimicking central mucoepidermoid carcinoma. J Oral Maxillofac Pathol. 2010;14(1):12-15.

21. Cláudio Maranhao Pereira, Danilo Santos Carneiro, Henryque Batista Climaco Pofahl, Patricia Freire Gasparetto, Alberto Freire Silva Junior. Calcifying cystic odontogenic tumor radiographically mimicking a lateral periodontal cyst: clinical case report. J Health Sci Inst. 2010;28(4):315317.

22. Shear M, Speight P. Cysts of the Oral and Maxillofacial Regions. In: Shear M, Speight $P$, editors. 4th ed. Blackwell Muunksgaard; 2007.

23. Bouzoubaa S, Khazana MM, Yahya IB. Keratocysts of the jaws: discordance between clinical, radiological and pathological diagnosis. Two cases report. Med Buccale Chir Buccale. 2013;19(2):131-137.

24. Cottom HE, Bshena FI, Speight PM, Craig GT, Jones AV. Histopathological features that predict the recurrence of odontogenic keratocysts. J Oral Pathol Med. 2012;41(5):408-414.

25. Martin-Duverneuil N, Sahli-Amor M, Chiras J. Imaging of odontogenic tumors of the maxilla. J Radiol. 2009;90(5):649660.

26. Warad NM, Sulabha AN, Sameer Choudhari, Suchitra G. An Unusual Presentation Of Dentigerous Cyst Involving the Maxillary Canine In a Young Boy. J Int Dent Med Res. 2012;5(2):114-117.

27. Teman G, Lacan A, Suissa M, Sarazin L. Stratégie des explorations en imagerie dentaire et maxillo faciale. EMC - Chirurgie orale et maxillo-faciale. 2011:1-11 [Article 22010-D-60].

28. Peron JM, Hardy $H$. Tumeurs odontogéniques mixtes. Revue de Stomatologie et de Chirurgie Maxillo-faciale. 2009;110(4)217-220.

29. Ahmad M, Freymiller E. Cone beam computed tomography: evaluation of maxillofacial pathology. J Calif Dent Assoc. 2010;38(1):41-47.

30. Hauret L, Hodez C. A new modality for dentomaxillofacial imaging: Cone beam CT. J Radiol. 2009;90(5):604-617.

31. Kramer IRH, Pindborg JJ, Shear M. Histological typing of odontogenic tumours. International histological classification of tumours, World Health Organization. 2nd ed. Berlin: Springer-Verlag; 1992.
32. Barthelemy I, Mondie JM. Giant cell tumors and pseudogiant cell tumors of the jaws. Rev Stomatol Chir Maxillofac. 2009;110(4)209-213.

33. Smit RB, Moore BK, Lou SM. Keratocystic Odontogenic Tumour of the Mandible: a case report of decompression with a customised removable tube and review of literature. N Z Dent J. 2015;111(3):98-101.

34. Amin Rahpeyma, Saeedeh Khajehahmadi. Marsupialization for Treatment of Jaw Cysts: Indications and Limitations. J Int Oral Health. 2016;8(2):158-162.

35. Willian Morais De Melo, Darklilson Pereira-Santos, Celso Koogi Sonoda, Eduardo Hochuli-Vieira. Decompression for Management of Keratocystic Odontogenic Tumor in the Mandible. J Craniofac Surg. 2012;23(6):639-640.

36. B. Ruhin, F. Guilbert, J.C Bertrand. Traitement des kystes, tumeurs et pseudotumeurs bénignes des maxillaires. Chirurgie orale et maxillo-faciale. EMC - Stomatologie. 2005;1(1):42-59.

37. Walid Ahmed Abdullah. Surgical treatment of keratocystic odontogenic tumour: A review article. Saudi Dent J. 2011;23(2):61-65.

38. S Balaji Tandri. Management of infected radicular cyst by surgical decompression. J Conserv Dent. 2010;13(3):159161.

39. Chao WC, Huang CC, Chang PH, Chen YL, Chen CW, Lee TJ. Management of nasolabial cysts by transnasal endoscopic marsupialization. Arch Otolaryngol Head Neck Surg. 2009;135(9): 932-935.

40. Nestal Zibo H, Miller E. Endoscopically assisted enucleation of a large mandibular periapical cyst. Stomatologija. 2011;13(4):128-131.

41. Dominiak M, Lysiak-Drwal K, Gedrange T, Zietek M, Gerber H. Efficacy of healing process of bone defects after apectomy: results after 6 and 12 months. J Physiol Pharmacol. 2009;60(Suppl 8):51-55.

42. Awni S, Conn B. Decompression of keratocystic odontogenic tumors leading to increased fibrosis, but without any change in epithelial proliferation. Oral Surg Oral Med Oral Pathol Oral Radiol. 2017;123(6):634-644.

43. Hyun-Soo Park, In-Seok Song, Byoung-Moo Seo, Jong-Ho Lee, Myung-Jin Kim. The effectiveness of decompression for patients with dentigerous cysts, keratocystic odontogenic tumors, and unicystic ameloblastoma. J Korean Assoc Oral Maxillofac Surg. 2014;40(6):260-265.

44. Thomas T, Martin A, Lafage-proust MH. Physiologie du tissu osseux. EMC - Appareil locomoteur. 2008;3:1-16. 